\title{
Hybrid Electric Vehicle Battery-Ultracapacitor Energy Management System Design and Optimization
}

\author{
Piotr A. Wozniak \\ Institute of Electrical Engineering Systems, Lodz University of Technology, \\ 90-924 Lodz, Poland \\ piotr.wozniak.1@p.lodz.pl
}

\begin{abstract}
The widespread use of internal combustion engines (ICEs) to power vehicles has serious negative consequences for the environment and human health. Therefore, for three decades, changes in the automotive industry have been observed aimed at total or partial electrification of vehicle drive systems. The effect of these activities are successively introduced to the consumer market vehicles with hybrid (HEV) and electric (EV) drives. This article proposes an original version of the energy management system in a hybrid vehicle. The capabilities of a hybrid energy storage system (HESS) consisting of batteries and ultracapacitors units were explored through simulation. The most important parameters of the proposed strategy have been optimized. The simulation tests conducted confirmed many benefits of using an additional energy source. The applied changes in the energy management system reduced the level of fuel consumption, the maximum temperature, and the value of the charging and discharging currents of the batteries. This makes it possible to extend the service life of primary energy storage and reduce operating costs. It also has a positive effect on the environment, not only by reducing the emission of harmful effects of combustion but also by reducing the costs of disposal of used batteries.
\end{abstract}

Index Terms-Energy management systems; Hybrid energy storage system; Hybrid electric vehicles; Supercapacitors.

\section{INTRODUCTION}

Fully electric vehicles (EVs) and hybrid vehicles (HEVs) are becoming more popular every year. The reasons for this are rising fuel prices and stricter environmental regulations. According to official statistics, sales of electric and hybrid cars exceeded 2,1 million in 2019 and the total number of registered vehicles of this type worldwide was more than 7 million. The percentage of electric cars represented $2.6 \%$ of global sales and about $1 \%$ of the global car fleet last year. Every year, the number of these vehicles increases by $40 \%$ [1].

All new cars produced for European market must meet the European emission standards. Every year the restrictions are more and more stringent and aim to limit the emission of harmful substances to the environment. The emission standards are defined in a series of directives from the European Union. The current standard for passenger cars is Euro 6d, introduced in 2018. The Euro 7 standard is already

Manuscript received 26 May, 2021; accepted 12 January, 2022. on the horizon, which will drastically tighten the requirements for emissions of harmful substances to such an extent that only hybrid and fully electric vehicles will be able to meet them. Euro 7 will be the final standard followed by the phasing-out of fossil fuel vehicles. According to the information provided by the European Parliament, the Euro 7 standard would apply in 2025 [2], [3].

To meet stringent standards for exhaust emission, manufacturers install small displacement engines in their cars. Small displacement of an engine means low power and torque, which in the case of larger cars has a negative impact on its performance. To solve this problem, manufacturers install turbochargers or mechanical compressors in the engines. As a result, the performance of small displacement engines is significantly improved. Unfortunately, this solution has disadvantages because drive units work under high load conditions, which means that they wear out faster and are more unreliable. This problem was eliminated in hybrid vehicles. The use of an electric motor guarantees high power and high torque in the entire speed range. As a result, the naturally aspirated engine with small displacement does not work under heavy loads, consumes less fuel and produces a low level of carbon oxides $(\mathrm{CO})$, nitrogen oxides $\left(\mathrm{NO}_{\mathrm{x}}\right)$, and hydrocarbons $(\mathrm{HC})$ [4]. Electric motors used in EV and HEV vehicles require electricity, which is typically stored in batteries. These energy storages reduce their capacity over time because of the large number of charge/discharge cycles. Rapid acceleration or braking of the vehicle causes the charging/discharging currents to reach high values. The flow of large amounts of energy leads to an increase in the temperature of the batteries. All of these factors cause irreversible chemical processes inside the battery, resulting in its degradation. To prevent this, batteries would have to be charged/discharged monotonically, which is impossible to achieve while driving a car [5].

The energy storage system, which is partially devoid of the aforementioned disadvantages, is a supercapacitor (ultracapacitor). Unlike a battery (BT), an ultracapacitor (UC) has a low energy density and therefore cannot be used as the main power source. Compared to a Li-ion battery with similar dimensions, the amount of stored energy is 20 times smaller. Additionally, the self-discharge speed of supercapacitors is much higher than in batteries (they can 
lose $10 \%$ to $20 \%$ of the charge per day), and therefore they are not suitable for long-term energy storage. The biggest advantage of supercapacitors is the ability to charge and discharge in a very short time (1000 times faster than batteries of similar capacity).

Much higher power density in compared to batteries and up to $1,000,000$ duty cycles (or 10-year life) makes them perfectly fulfil the role in applications at the high shock and vibration environments that require a large number of charging and discharging cycles. Moreover, operation at high temperatures does not adversely affect service life [6], [7]. The fusion of these two types of energy storage eliminates the weaknesses of each other, and their cooperation brings benefits. During rapid accelerations, supercapacitors will be able to cover the demand for a large amount of power or, in the case of braking, take this power, and when the car is driven at low speeds, the batteries will be used. Therefore, for the cooperation of batteries and supercapacitors, systems that control the energy flow and their operating parameters are needed.

Although the concept of using a hybrid energy storage system consisting of a battery and a supercapacitor is well known and documented in the literature, it is still open and new propositions in this area are needed. In [8], the effects of combining the two energy sources (battery and supercapacitor) were studied for the parallel drivetrain. The authors proposed using the appropriate table to proportionally send power to the battery and supercapacitor for charging relative to the state of charge (SOC) of each component. When the two energy storage systems (ESSs) were combined in parallel, the desired storage and peak current characteristics were achieved. Two hybrid power systems are proposed for vehicle applications: a fuel cell battery hybrid powertrain and a fuel cell - supercapacitor hybrid powertrain [9]. The default fuel cell vehicle with battery modelled in ADVISOR was used as a baseline vehicle. The paper in [10] deals with different modelling and simulation methods for electric and hybrid vehicles, and as an application example, ADVISOR is used to simulate a hybrid battery/supercapacitor energy storage system, the same as proposed in [8]. In [11], a simple and efficient rulebased power split strategy is proposed for a combined battery/supercapacitor energy storage system in hybrid electric vehicles. The performance of the proposed strategy has been tested on a hybrid electric city bus developed in MATLAB/Simulink. A hybrid battery/supercapacitor energy storage system for electric vehicles is deeply considered in [6]. The main objective was to provide an overview of recent advances in battery/supercapacitor design, performance, modelling and simulation, and energy management system (EMS) for EV application. In [12], a hybrid energy storage system (HESS) comprising Li-ion batteries and supercapacitors is modelled to evaluate its performance in electric vehicles under different driving cycles. The paper in [13] proposed a methodology for the optimal size of HESS consisting of fuel cells as the main energy source and a hybrid storage system based on battery banks and supercapacitors. An urban transport bus was used as a baseline vehicle. An overview of solutions for hybridization of energy storage was given in [14]. The article proposes a method that leads to reduction of losses in electric storage system by using a new switching strategy. In [15], the equivalent fuel consumption during parallel charging of a semi-active HESS was introduced in a seriesparallel HEV under EMS based on rules and a fuzzy logicbased control strategy for the HESS was established. Similarly, as in [14], an urban transport bus was used as the baseline vehicle. A supercapacitor/Li-ion Battery Hybrid System and a rule-based energy management strategy for EV were considered in paper in [16]. In [17], the authors designed EMS for a Hybrid Electric Vehicle based on Deep Reinforcement Learning. The system can learn to select actions directly from the states without any prediction or predefined rules. Simulation results demonstrate that DRLbased EMS can perform better in fuel economy. All the works discussed and the previous experience of the authors show the benefits of hybridization of energy storage. In [18], the authors formulate and solve a multiobjective optimization problem to optimize the weight of the HESS and the life of the battery cycle. The proposed optimization framework is very flexible and can be easily adapted to different optimization objectives. The authors claim that the use of 72 UC cells and optimized HESS in urban driving situations can extend the battery lifetime by $76 \%$. The authors in [19] applied HESS to improve the performance and integration of the electric vehicle power train. The results of the simulation and experiments confirm the effectiveness of the proposed system and the control strategy. In [20], the authors propose an equivalent series resistance ESR-based control, namely a circuit-level approach, to efficiently distribute load in hybrid energy storage systems of battery-ultracapacitors. Compared to the battery system, the total energy loss and the rise of the battery temperature in the example HESS are averagely reduced by $44.9 \%$ and $51.9 \%$, respectively, under the proposed ESR-based control. The article in [21] presents an EMS for a battery-ultracapacitor HESS that includes a bidirectional multi-input converter (MIC) for electric vehicles. Because the energy flow between the battery and the ultracapacitor is free in this MIC, the proposed EMS regulates not only the state of charge of the UC, but also smooths the battery power profile by using a fuzzy logic controller and a rate limiter. Therefore, it results in a sustainable HESS with a longer battery life. In [22], optimization of the control parameters for a power-split $\mathrm{HEV}$ with ultracapacitors is addressed to achieve better fuel economy. After optimization, the fuel saving rate reaches $9.20 \%$ in the urban section, $6.40 \%$ in the roadway section, and $5.40 \%$ in freeway section. In [23], a novel multi-input converter MIC is proposed to interface a batterysupercapacitor combination that reduces the required converter rating to meet the surge power needs of the load. In [24], energy storage system is developed to mitigate battery degradation in electric vehicles. By coordinating the battery and supercapacitor, the proposed system avoids using the large bidirectional DC/DC converter. In [25], a simulation model, calibrated and validated on an engine testbed, has been used to evaluate the performance of a hybrid storage HEV microcar under different operative conditions. The results show that the hybridization of the powertrain may reduce fuel consumption by up to $27 \%$, while the battery lifetime may be more than doubled. The 
authors of the article in [26] emphasize the great importance of the energy management system and present the current and future trends in the field of EMS. Objectives, such as reducing fuel consumption and releasing harmful substances, are achievable only if energy flow is optimally managed. Hence, EMS has become an integral part of the overall vehicle control module. The authors reviewed 250 research articles from the period 1993-2018 in terms of the applied control strategy for energy management. As a result, they present current and future trends, advantages and disadvantages, and problems that accompany the EMS. One of the main problems raised by the authors is that most of the research has focused individually on reducing fuel consumption or minimizing emissions. While EMS should also satisfy the power demand from the vehicle and constrain battery state of charge within allowable limits. Because of this, we maintain driving comfort and minimize the degradation of battery health. One more issue that the authors raised is that the control strategy of the energy management system should be competent enough to operate the ICE always within its optimum efficiency zone. The characteristic of an internal combustion engine is such that the operating zone with maximum efficiency can only satisfy the objective of reducing fuel consumption, but does not suffice to the objective of minimization of pollutant emission. Among all the control methods mentioned, there were about 15 of them, the authors highlight the importance of rule-based control strategies in real-time applications. This method is still in use today.

The article presents the original energy management system in a hybrid vehicle equipped with second energy storage in the form of a supercapacitor. The most important parameters of the proposed strategy have been optimized. Two optimization methods were used: DIviding RECTangles (DIRECT) algorithm [27] and nondominated sorting genetic algorithm II (NSGA-II) [28]. Appropriate objective functions have been proposed, enabling optimization in terms of both fuel consumption, emission of harmful substances, as well as the ability to climb hills and acceleration values. A large number of simulation tests carried out confirmed that the use of an additional energy storage system and the proposed management strategy allowed the reduction of fuel consumption, maximum battery temperature, and the value of charging and discharging currents. As a result, it allows one to extend the battery life and reduce operating costs. The proposed energy management strategy is discussed in Section II, and the results of simulations and comparisons are given in Section III. Section IV provides the conclusions.

\section{THE PROPOSED APPROACH}

\section{A. Simulation Package Used}

The simulations were performed using the Matlab program with the ADVISOR (ADvanced VehIcle SimulatOR) overlay, created by the NREL company. This program is designed for a quick analysis of the performance and fuel economy of electric and hybrid vehicles [29]. The simulator was and is used by a wide group of users. Initially, approximately $2 / 3$ of the users were from the industrial sector, including Ford Motor Company, Delphi Automotive
Systems, and General Motors Corp. Other users are universities and research centres. The described program allows estimating fuel consumption, the emission of harmful substances for various driving cycles, and the calculation of energy losses in drive systems in hybrid and fully electric vehicles. ADVISOR is equipped with a user-friendly Graphical User Interface (GUI), which makes it easy to use and accelerates simulation research. The modular structure of the program makes the built-in models relatively easy to expand and improve. The development of new models of driveline components and control systems requires deep knowledge of the Simulink environment [10], [30]-[32]. There are many simulation programs available on the market, such as AVL CRUISE [33], AMESim [34], Autonomie [35], and PSIM [36], but the purchase of a license for them is associated with high costs. Therefore, it was decided to use open-source software. The Advisor and Future Automotive Systems Technology Simulator (FASTSim) belong to this software category. Both vehicle simulators were developed by the US National Renewable Energy Lab. FASTSim is a newer program, but compared to its predecessor ADVISOR, it has been significantly simplified. FASTSim provides a simple way to compare vehicle powertrains, including conventional internal combustion engines (ICE), hybrids, battery electrics, and fuel cell vehicles. Efficiency, cost, performance, battery life, and $\mathrm{CO} 2$ emissions can also be obtained. The ADVISOR simulator is much more advanced; it gives more possibilities to modify models and simulation parameters [37]. Although ADVISOR is older than FASTSim, the simulation results are almost identical. This is evidenced by the research carried out, e.g., in the article in [38]. Developed between 1994 and 2004, ADVISOR's open-source code remains popular today [39]. The purpose of GUI ADVISOR is to enable the user to understand the essence of the software and to ensure that he can quickly master the use of embedded models and create his own. Vehicle models implemented in the advisor program make it possible to examine the impact of vehicle accessories (i.e., air conditioning or heating) on fuel consumption and exhaust emissions. Ambient temperature can be taken into account during the simulation, so the results obtained can be seasonally dependent. ADVISOR is what is called a "backward-facing vehicle simulation", due to this flow of information back through the drivetrain, from tire to axle to gearbox, etc. To reflect the driver's temperament and driving style, forward-facing vehicle simulations are used. ADVISOR is well suited to evaluate design control logic and energy management strategies but cannot reflect the driving style of driver. The Advisor simulator can also work in batch mode. This is an important feature in the case of integration with other computing packages, including the optimization procedures used at work. This advantage also played a role in the decision to choose this software.

\section{B. Vehicle Description and Proposed Energy Management Strategy}

The article attempts to modify the Toyota Prius vehicle, which was the subject of the author's preliminary research presented in [40]. Second energy storage in the form of a supercapacitor pack has been added to the standard version 
of the Prius initially powered by the Ni-MH battery pack. In [40], the author proposed a different logic for energy management of the storage system, without optimizing its parameters. Although the system had a complex logical structure, it was taken into account only a high demand for power, e.g., rapid acceleration. In the strategy proposed in this paper, the control strategy takes into account the possibility of limiting battery operation after exceeding the critical value of temperature and, in addition to the classic rule-based approach, enables the use of the GPS signal, knowledge of the route, and its profile to adequately predict the possibility of charging/discharging batteries and ultracapacitors. Changing the number of batteries and adding an additional supercapacitor pack leads to a change in vehicle weight, which was automatically taken into account by the program. Two DC/DC converters were added to the modified version of the Prius, and their weight $(16 \mathrm{~kg})$ was also added to the vehicle weight. The efficiency of both converters was assumed to be 0.95 and was taken into account in the vehicle model. The bus voltage was set to $300 \mathrm{~V}$. The most important advantage of the HEV model on which the research is carried out is that the model is a representation of a real Toyota Prius and the simulation results are close to the values achieved under real conditions. Other models available in ADVISOR are usually simplified, less reliable, and creating your own model is a very complex and month-long issue. The Toyota Prius model, created by the authors of ADVISOR, has been thoroughly tested and is fully reliable [41], [42]. The proposed energy management strategy is general and can be easily adapted to other models of hybrid vehicles. Most of the strategies known from the literature focus either on vehicle prototypes or focus only on simulation research. Therefore, the author's intention was to verify the proposed strategy on a vehicle model that was subjected to detailed laboratory tests. A proposal that proves effective for a massproduced car model seems more plausible than if the same concept was applied to a prototype model devoid of extensive laboratory testing. The block diagram of the Toyota Prius is shown in Fig. 1.

The factory version supports only one energy storage in the form of a Ni-MH battery pack and does not have a block "Energy storage system (UC)". The block "Power bus" has been modified to properly manage two energy storage. For the purposes of this paper, the factory version of the Toyota Prius will be called "v1.0", while the version presented in this paper was marked as "v2.0". The control system takes into account additional factors in the energy management process and uses a rule-based control strategy.

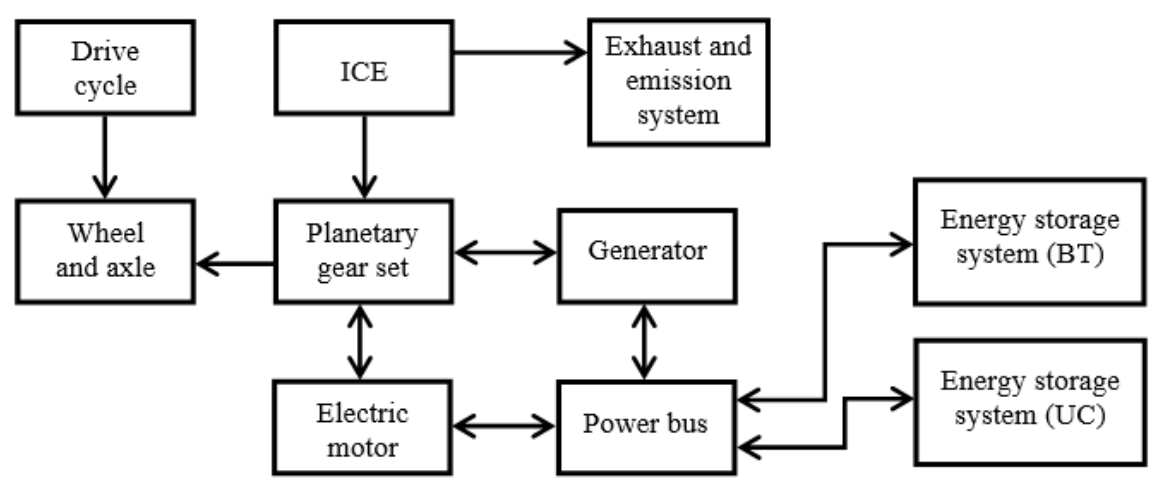

Fig. 1. Toyota Prius block diagram.

The controller reports the demand for instantaneous power from energy storage, taking into account the power required by the accessories and the generator. This part is analogous to the original Toyota Prius. According to the convention used in the ADVISOR program, the negative sign of power means the possibility of recharging the ESS/ESS, while the positive sign of power means the demand for power from the reservoirs. The main goal was to develop an effective method of cooperation between two types of energy storage: battery and ultracapacitor. Therefore, the powertrain was modified using a fully active parallel hybrid topology with two bidirectional DC/DC converters.

The main elements of the proposed energy flow management system between storage tanks will be discussed in more detail. We can specify a few blocks in the system (Fig. 2):

1. Two SOC limit blocks for main (battery) and auxiliary (ultracapacitor) energy storage. The output of each block

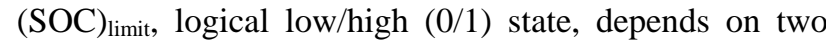
variables and two preset parameters. The variables are the current SOC value of the BT/UC storage, the sign of the instantaneous power $\mathrm{P}_{\text {sign }}(1$ - positive power,-1 - negative power), and the parameters: $S_{L}$ and $S_{H}$ - lowest/highest desired state of charge for each energy storage (set parameters $\left(\mathrm{S}_{\mathrm{L}}\right)_{\mathrm{BT}}=0.45,\left(\mathrm{~S}_{\mathrm{H}}\right)_{\mathrm{BT}}=0.75$ - values as in the original Prius model, and $\left(\mathrm{S}_{\mathrm{L}}\right)_{\mathrm{UC}}=0.05,\left(\mathrm{~S}_{\mathrm{H}}\right)_{\mathrm{UC}}=0.95$ for the auxiliary energy storage). The signal $\mathrm{SOC}_{\text {limit }}$ is the negation of the auxiliary logical value $S$ calculated according to the rule

$$
\mathrm{S}=\left\{\begin{array}{l}
1 \text { if }\left(\left(\mathrm{P}_{\text {sign }}=1\right) \wedge\left(\mathrm{SOC} \leq \mathrm{S}_{\mathrm{L}}\right)\right) \vee, \\
\left(\left(\mathrm{P}_{\text {sign }}=-1\right) \wedge\left(\mathrm{SOC} \geq \mathrm{S}_{\mathrm{H}}\right)\right), \\
0-\text { otherwise. }
\end{array}\right.
$$

2. Block for limiting the main energy storage temperature by redirecting the desired power (charging/discharging) to the auxiliary energy storage (UC), if its current SOC state allows it. The block output signal $\mathrm{T}_{\text {limit, }}$ logic low/high $(0 / 1)$ depends on two variables and two preset parameters. The variables are the current value of the main energy storage temperature of $\mathrm{T}_{\mathrm{BT}}$ and the logical value of the BT signal from the previous step $\mathrm{BT}_{-1}(1 / 0$ - the battery 
was/was not used in the previous step). The parameters are two temperature limits $\left(\mathrm{T}^{+}, \mathrm{T}^{-}\right)$- defining the width of the hysteresis loop. In the simulations presented in the article, $\mathrm{T}^{+}=30^{\circ} \mathrm{C}, \mathrm{T}^{-}=28^{\circ} \mathrm{C}$ were assumed.

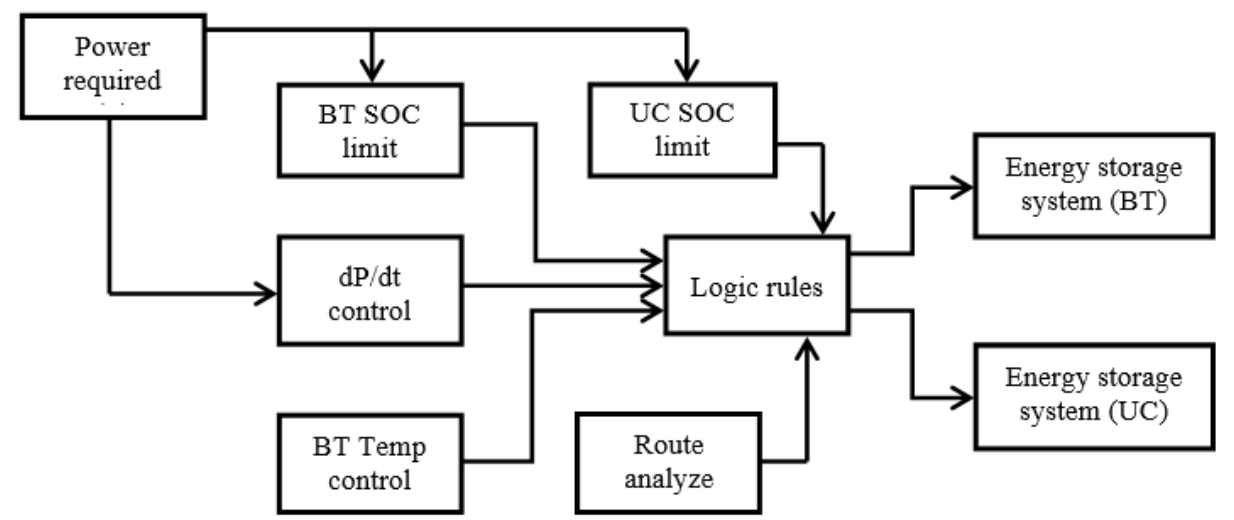

Fig. 2. Power Bus block diagram.

Logical value $\mathrm{T}_{\text {limit }}=1$, when only the UC storage is to be enabled, 0 when it is possible to operate the BT storage or both, according to the following rules

$$
\mathrm{T}_{\text {limit }}=\left\{\begin{array}{l}
1 \text { if }\left(\left(\mathrm{T}_{\mathrm{BT}}>\mathrm{T}^{+}\right) \vee,\right. \\
\left(\left(\mathrm{T}_{\mathrm{BT}} \in\left[\mathrm{T}^{-}, \mathrm{T}^{+}\right]\right) \wedge\left(\mathrm{BT}_{-1}=0\right)\right), \\
0-\text { otherwise. }
\end{array}\right.
$$

3. Block to determine the absolute value of the time derivative of power. The logical output $D_{p}$ of the block depends on the optimized parameter $\mathrm{D}_{\mathrm{f}}$, and its value is equal to 1 , if $|\mathrm{dP} / \mathrm{dt}|>\mathrm{D}_{\mathrm{f}}$, where $\mathrm{P}$ is the instantaneous power and $\mathrm{dP} / \mathrm{dt}$ approximates the derivative of the input signal $\mathrm{P}$ with respect to the simulation time $\mathrm{t}$ by computing a numerical difference $\Delta \mathrm{P} / \Delta \mathrm{t}$, where $\Delta \mathrm{P}$ is the change in input value and $\Delta \mathrm{t}$ is the change in time since the previous simulation time step. Moreover, the block has two additional logical outputs $\left(D_{1}, D_{2}\right)$ depending on the current SOC state of the UC storage, the sign of the instantaneous power $\mathrm{P}_{\text {sign }}$, and two optimized parameters $\left(\mathrm{S}_{\mathrm{A}}, \mathrm{S}_{\mathrm{B}}\right)$. Their logical values are determined according to the rules:

$$
\begin{gathered}
D_{1}=\left\{\begin{array}{l}
1 \text { if }\left(\left(P_{\text {sign }}=1\right) \wedge\left(D_{p}=1\right) \wedge\left(\text { SOC }>S_{B}\right)\right), \\
0-\text { otherwise },
\end{array}\right. \\
D_{1}=\left\{\begin{array}{l}
1 \text { if }\left(\left(P_{\text {sign }}=-1\right) \wedge\left(D_{p}=1\right) \wedge\left(\text { SOC }>S_{A}\right)\right), \\
0-\text { otherwise }
\end{array}\right.
\end{gathered}
$$

4. Block for checking the a priori knowledge of planned route profile, cooperating in real-time with the GPS. Its role is to use the available energy stored in the UC storage system just before the local peak (maximum) if only the average slope of the route after reaching the peak is negative, which will allow immediate recharging of the UC storage system by means of energy recovery during braking. Based on the information about the route profile, the algorithm determines the local maxima of the curve defining the route profile, and then checks whether in the route section with a given length $\mathrm{L}$ (assumed value $\mathrm{L}=$ $200 \mathrm{~m}$ ) to the left and right of the top of the hill, the average slope exceeds the set $\mathrm{G}$ value $(+0.5 \%$ left and $0.5 \%$ to the right of the top). Moreover, the algorithm eliminates local maxima located close to each other (it was assumed that the minimum distance between two local maxima is not less than $400 \mathrm{~m}$ ). The algorithm is simple and has low hardware requirements. It is planned to perform calculations according to the proposed algorithm immediately before starting the route and save in the look-up table the start and end points of the intervals in which the UC storage is additionally used (if the current value of SOC allows it). The output signal G is equal to 1 if the current vehicle position is within the specified ranges. The result of the algorithm's operation is shown in Fig. 3 for the part of VAIL2NREL route. Due to the limited availability of profile routes (NREL2VAIL and VAIL2NREL in ADVISOR), the $\mathrm{L}$ and $\mathrm{G}$ values were not optimized, they were determined based on certain observations and design assumptions (e.g., the maximum energy stored in the UC storage with a given number of modules). As a part of further work, registration of routes with a profile in urban conditions is planned, which will allow for more extensive research, including optimization.

The sketch of the rule-based energy management strategy. Let us define the auxiliary logical variables:

$$
\begin{aligned}
& -\mathrm{A}=\left(\mathrm{D}_{1}=1\right) \vee\left(\mathrm{D}_{2}=1\right) \vee\left(\mathrm{T}_{\text {limit }}=1\right) ; \\
& -\mathrm{B}=\mathrm{NOT}(\mathrm{A}) ; \\
& -\mathrm{C}=\left(\mathrm{D}_{\mathrm{p}}=1\right) \vee(\mathrm{G}=1) .
\end{aligned}
$$

After defining the output signals of individual blocks and the variables, the strategy for controlling the energy flow between the BT and UC storage systems can be presented in the form of the following rules.

- rule 1 :

$$
\mathrm{UC}=\left\{\begin{array}{l}
1 \text { if } \mathrm{A} \vee \mathrm{C}] \wedge\left(\mathrm{SOC}_{\text {limitUC }}=1\right), \\
0-\text { otherwise }
\end{array}\right.
$$

- rule 2:

$$
\mathrm{BT}=\left\{\begin{array}{l}
1 \text { if } \mathrm{B} \vee \mathrm{C}] \wedge\left(\mathrm{SOC}_{\text {limitBT }}=1\right), \\
0-\text { otherwise }
\end{array}\right.
$$




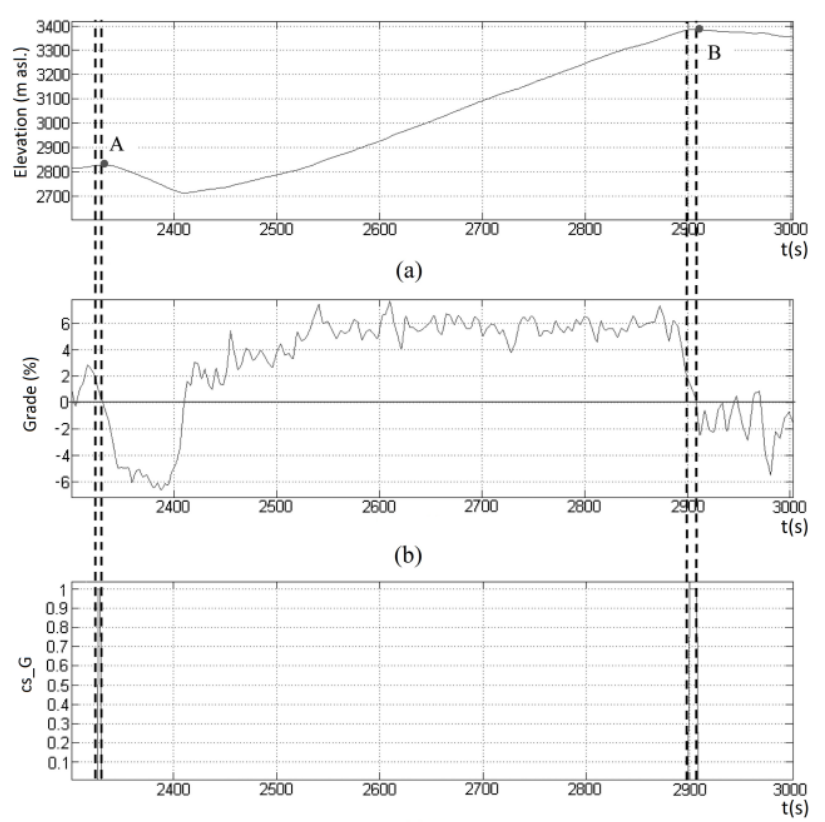

(c)

Fig. 3. Parts of the VAIL2NREL route simulation runs: (a) the elevation plot with local maximum points (A and $\mathrm{B}$ ) selected by the proposed algorithm; (b) the plot of grade; (c) the signal G plot.

\section{OPtIMIZATION, SiMULATIONS, AND DISCUSSION OF THE RESULTS}

\section{A. Initial Research}

In the initial phase of the investigation, 19 routes were considered (Table I). For the simulation results to be reliable and not significantly dependent on the initial value of energy stored in ESSs, all considered routes are longer than $20 \mathrm{~km}$ (the designation $\mathrm{xn}$ in a given route means the number of times the given route is repeated to obtain the assumed total length). The following parameters were assumed in all the simulations in the paper: $\left(\mathrm{S}_{\mathrm{L}}\right)_{\mathrm{BT}}=0.45,\left(\mathrm{~S}_{\mathrm{H}}\right)_{\mathrm{BT}}=0.75,\left(\mathrm{~S}_{\mathrm{L}}\right)_{\mathrm{UC}}$ $=0.05,\left(\mathrm{~S}_{\mathrm{H}}\right)_{\mathrm{UC}}=0.95$. Furthermore, it was assumed that the starting SOC values of BT and UC were $\mathrm{S}_{\mathrm{BT} 0}=0.7, \mathrm{~S}_{\mathrm{UC} 0}=$ 0.5 . Table I also includes fuel consumption and harmful substances emissions for Prius v1.0 (original Prius model). In Table I, two driving cycles WLTC_3 and Lodz2, in addition to the routes available in ADVISOR, have been added. The author developed the Lodz2 driving cycle for the urban agglomeration of the city of Lodz. Data acquisition was made via the OBD2 interface during rush hour driving in the city centre.

\section{B. Single Objective Optimization}

Next, the selected parameters of the proposed strategy $\left(\mathrm{N}_{\mathrm{BT}}\right.$ - number of battery modules, $\mathrm{N}_{\mathrm{UC}}$ - number of ultracapacitor modules, and $\mathrm{D}_{\mathrm{f}}, \mathrm{S}_{\mathrm{A}}, \mathrm{S}_{\mathrm{B}}$ defined in the previous section) were optimized for each of the routes individually using the DIRECT algorithm [20]. This type of algorithm requires no knowledge of the gradient of the objective function. The Direct algorithm samples points in the domain and uses the information it has obtained to decide where to search next. This is why it is very useful when the objective function is a "black box" function or simulation. Nevertheless, the results obtained had a wide range of the parameters. It should be noted that variables $D_{f}$, $\mathrm{S}_{\mathrm{A}}, \mathrm{S}_{\mathrm{B}}$ can be changed depending on the driving style and type of route, but the number of batteries and supercapacitors must be constant and optimal so that the vehicle can work in any road conditions. Therefore, it was decided to create aggregated routes based on the owned routes. Three route configurations with different properties have been developed: CITY $(76.5 \mathrm{~km})$ - a typical urban route with an average speed of $18.5 \mathrm{~km} / \mathrm{h}$, HIGH $(116.7 \mathrm{~km})$ - a suburban route with an average speed of $68 \mathrm{~km} / \mathrm{h}$, and HIGH $2(117.4 \mathrm{~km})$ - a route with an average speed of $88 \mathrm{~km} / \mathrm{h}$. The routes are a combination of the appropriate routes presented in Table I,

$$
\begin{gathered}
\text { CITY }=\text { INDIA_URBAN }+3 \times(\text { Lodz } 2)+3 \times(\text { Manhattan }) \\
+5 \times(\text { NYCC })+2 \times(\text { sc03 })+\text { UDDS }+ \text { UNIF01, } \\
\text { HIGH }=\text { WLTC_ } 3+\text { US06 + Rep_05 + ARB02 + HWFET, } \\
\text { HIGH2 }=2 \times(\text { Cleveland })+2 \times(\text { Rep_05 })+2 \times \\
(\text { US06HWY }),
\end{gathered}
$$

respectively, where the integer preceding the route designator, if exists, represents the number of times the given route is repeated. Detailed information and speed percentages for the CITY, HIGH, and $\mathrm{HIGH} 2$ routes are shown in Figs. 4-6. Fuel consumption and harmful substance emissions for the Prius v1.0 model are presented

\begin{tabular}{|c|c|c|c|c|c|c|}
\hline No. & Route & Distance $[\mathrm{km}]$ & FC $[1 / 100 ~ k m]$ & $\mathrm{HC}[\mathrm{g} / \mathrm{km}]$ & CO [g/km] & NOx $[\mathrm{g} / \mathrm{km}]$ \\
\hline 1 & WLTC_3 & 23.20 & 5.2 & 0.432 & 0.465 & 0.116 \\
\hline 2 & INDIA_URBAN x 2 & 35.00 & 5.5 & 0.394 & 0.427 & 0.109 \\
\hline 3 & Lodz2 $\times 8$ & 28.40 & 7.5 & 0.475 & 0.554 & 0.159 \\
\hline 5 & NYCC x15 & 28.30 & 11.2 & 0.641 & 0.609 & 0.163 \\
\hline 6 & NurembergR36 x6 & 25.90 & 8.6 & 0.586 & 0.551 & 0.121 \\
\hline 7 & Rep_05 x1 & 32.25 & 5.7 & 0.312 & 0.500 & 0.197 \\
\hline 8 & $\mathrm{sc} 03 \times 5$ & 28.80 & 5.3 & 0.384 & 0.440 & 0.126 \\
\hline 9 & skeleton $\times 30$ & 21.60 & 7.7 & 0.520 & 0.685 & 0.226 \\
\hline 10 & UDDS x 2 & 24.00 & 5.1 & 0.439 & 0.489 & 0.120 \\
\hline 11 & UNIF01 x1 & 22.00 & 5.5 & 0.436 & 0.513 & 0.145 \\
\hline 12 & US06 x2 & 25.70 & 6.5 & 0.370 & 0.569 & 0.222 \\
\hline 13 & Vail2Nrel (prof) x1 & 139.3 & 4.7 & 0.157 & 0.195 & 0.098 \\
\hline 14 & Wvucity x5 & 26.60 & 7.8 & 0.576 & 0.529 & 0.099 \\
\hline 15 & Wvusub x2 & 23.90 & 5.0 & 0.456 & 0.471 & 0.098 \\
\hline 16 & ARB02 & 31.91 & 6.4 & 0.334 & 0.487 & 0.191 \\
\hline 18 & Cleveland 2x & 32.86 & 8.7 & 0.393 & 0.554 & 0.239 \\
\hline 19 & US06HWY 3x & 30.12 & 5.9 & 0.324 & 0.531 & 0.210 \\
\hline
\end{tabular}
in Table II. In addition, some acceleration tests and a gradeability test will be run. Both ESSs were used in both tests.

TABLE I. THE CONSIDERED ROUTES, FUEL CONSUMPTION AND EMISSIONS OF HARMFUL SUBSTANCES FOR PRIUS V1.0. 
TABLE II. THE AGGREGATED ROUTES, FUEL CONSUMPTION AND EMISSIONS OF HARMFUL SUBSTANCES FOR PRIUS V1.0.

\begin{tabular}{|c|c|c|c|c|c|c|}
\hline No. & Route & Distance $[\mathbf{k m}]$ & $\mathbf{F C}[\mathbf{1} / \mathbf{1 0 0} \mathbf{~ k m}]$ & $\mathbf{H C}[\mathbf{g} / \mathbf{k m}]$ & $\mathbf{C O}[\mathbf{g} / \mathbf{k m}]$ & $\mathbf{N O x}[\mathbf{g} / \mathbf{k m}]$ \\
\hline 1 & CITY & 76.46 & 7.3 & 0.350 & 0.358 & 0.118 \\
\hline 2 & HIGH & 116.77 & 5.8 & 0.187 & 0.250 & 0.131 \\
\hline 3 & HIGH2 & 117.43 & 6.8 & 0.203 & 0.273 & 0.152 \\
\hline
\end{tabular}

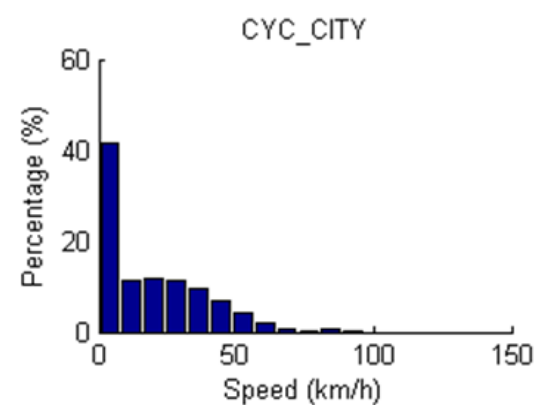

(a)

\begin{tabular}{|rc|}
\hline time: & $14846 \mathrm{~s}$ \\
distance: & $76.46 \mathrm{~km}$ \\
max speed: & $91.25 \mathrm{~km} / \mathrm{h}$ \\
avg speed: & $18.54 \mathrm{~km} / \mathrm{h}$ \\
idle time: & $3986 \mathrm{~s}$ \\
no. of stops: & 269 \\
\hline
\end{tabular}

(b)

Fig. 4. CITY drive cycle: (a) percentage share of speed; (b) main route parameters.

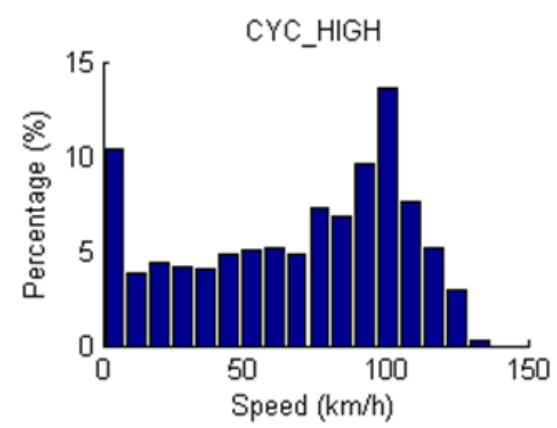

(a)

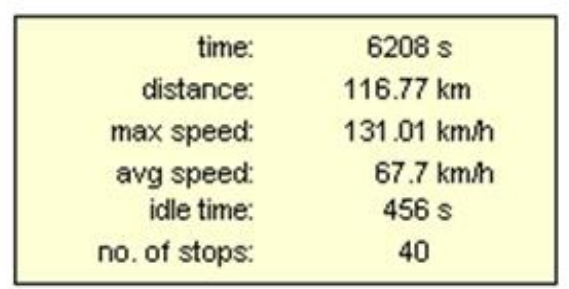

(b)

Fig. 5. HIGH drive cycle: (a) percentage share of speed; (b) main route parameters.

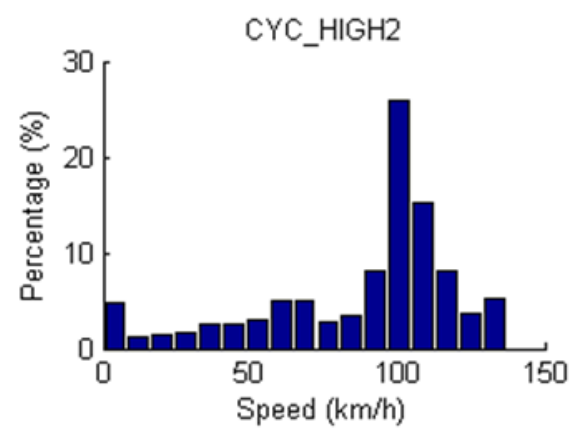

(a)

\begin{tabular}{|rc|}
\hline time: & $4809 \mathrm{~s}$ \\
distance: & $117.43 \mathrm{~km}$ \\
max speed: & $161.63 \mathrm{~km} / \mathrm{h}$ \\
avg speed: & $87.89 \mathrm{~km} / \mathrm{h}$ \\
idle time: & $138 \mathrm{~s}$ \\
no. of stops: & 20 \\
\hline
\end{tabular}

(b)

Fig. 6. HIGH2 drive cycle: (a) percentage share of speed; (b) main route parameters.

Acceleration times $a_{1}(0 \mathrm{~km} / \mathrm{h}-40 \mathrm{~km} / \mathrm{h}), a_{2}(40 \mathrm{~km} / \mathrm{h}-$ $60 \mathrm{~km} / \mathrm{h})$, and $\mathrm{a}_{3}(0 \mathrm{~km} / \mathrm{h}-60 \mathrm{~km} / \mathrm{h})$ were determined in the acceleration test. Speed thresholds were established with the aim of optimizing vehicle parameters for urban conditions. The gradeability test (value $\mathrm{g}$ in $\%$ ) was performed at a speed of $50 \mathrm{~km} / \mathrm{h}$. The following results were obtained for the original Prius model: $\mathrm{a}_{1}=4.30 \mathrm{~s}, \mathrm{a}_{2}=3.25 \mathrm{~s}, \mathrm{a}_{3}=7.60 \mathrm{~s}$, $\mathrm{g}=14.4 \%$. Figure 7 shows CITY drive cycle simulation results for the original Toyota Prius model.

To carry out the optimization process using the DIRECT algorithm, the parameters to be optimized (vector $\mathbf{x}=\left[\mathrm{N}_{\mathrm{BT}}\right.$, $\left.\mathrm{N}_{\mathrm{UC}}, \mathrm{D}_{\mathrm{f}}, \mathrm{S}_{\mathrm{A}}, \mathrm{S}_{\mathrm{B}}\right]^{\mathrm{T}}, \mathrm{T}$ - denotes transposition) and the objective function were selected. The lower bounds $\mathbf{x}_{\mathbf{L}}$ and the upper bounds $\mathbf{x}_{\mathbf{U}}$ for vector $\mathbf{x}$ are assumed as follows $\mathbf{x}_{\mathbf{L}}$ $=\left[\begin{array}{lllll}20 & 20 & 100 & 0.05 & 0.05\end{array}\right]^{\mathrm{T}}, \mathbf{x}_{\mathbf{U}}=\left[\begin{array}{lllll}35 & 80 & 15000 & 0.95 & 0.95\end{array}\right]^{\mathrm{T}}$. The objective function was selected in the following form

$$
\begin{gathered}
\mathrm{f}=\mathrm{w}_{1} \frac{\mathrm{F}_{\mathrm{c}}}{\mathrm{F}_{\mathrm{c} 1}}+\mathrm{w}_{2} \frac{\mathrm{E}_{\mathrm{HC}}}{\mathrm{E}_{\mathrm{HC} 1}}+\mathrm{w}_{3} \frac{\mathrm{E}_{\mathrm{CO}}}{\mathrm{E}_{\mathrm{CO} 1}}+\mathrm{w}_{4} \frac{\mathrm{E}_{\mathrm{NOX}}}{\mathrm{E}_{\mathrm{NOX} 1}}+ \\
+\mathrm{w}_{5} \frac{\mathrm{g}_{1}}{\mathrm{~g}}+\mathrm{w}_{6} \frac{\mathrm{a}_{\mathrm{c} 1}}{\mathrm{a}_{1}}+\mathrm{w}_{7} \frac{\mathrm{a}_{\mathrm{c} 2}}{\mathrm{a}_{2}}+\mathrm{w}_{8} \frac{\mathrm{a}_{\mathrm{cs}}}{\mathrm{a}_{\mathrm{s}}},
\end{gathered}
$$

where $\mathrm{w}_{\mathrm{i}}, \mathrm{i}=1, \ldots, 8$, denotes respective weights, $\mathrm{F}_{\mathrm{c}}$ - fuel consumption, $F_{\mathrm{c} 1}$ - fuel consumption of the original Prius model on the same route. $E_{j}$ - tailpipe emissions $(j=H C$, $\mathrm{CO}$, and $\left.\mathrm{NO}_{\mathrm{X}}\right), \mathrm{E}_{\mathrm{j} 1}$ - tailpipe emissions for the original Prius model on the same route $\left(\mathrm{j}=\mathrm{HC}, \mathrm{CO}\right.$, and $\left.\mathrm{NO}_{\mathrm{X}}\right), \mathrm{g}_{1}-$ gradeability, $\mathrm{g}$ - gradeability for the original Prius model, $\mathrm{a}_{\mathrm{ci}}$, $i=1, \ldots, 3$, acceleration times, $a_{i}$ - acceleration times for the original Prius model. The change of weights allows the significance of the corresponding quantity to increase in the objective function. The following weight values were assumed: $0.75,0.02,0.02,0.02,0.10,0.03,0.03,0.03$. A complete optimization process was carried out for these routes, and the parameters $\mathrm{N}_{\mathrm{BT}}, \mathrm{N}_{\mathrm{UC}}, \mathrm{D}_{\mathrm{f}}, \mathrm{S}_{\mathrm{A}}, \mathrm{S}_{\mathrm{B}}$ were obtained. The results for the CITY drive cycle are as follows: $\mathrm{N}_{\mathrm{BT}}=35, \mathrm{~N}_{\mathrm{UC}}=77, \mathrm{D}_{\mathrm{f}}=2398, \mathrm{~S}_{\mathrm{A}}=0.1333, \mathrm{~S}_{\mathrm{B}}=$ $0.1000, \mathrm{~F}_{\mathrm{c}}=6.7074, \mathrm{E}_{\mathrm{HC}}=0.3411, \mathrm{E}_{\mathrm{CO}}=0.3517, \mathrm{E}_{\mathrm{NOX}}=$ $0.1089, \mathrm{~g}=16.753, \mathrm{a}_{\mathrm{c} 1}=4.2813, \mathrm{a}_{\mathrm{c} 2}=3.3792, \mathrm{a}_{\mathrm{c} 3}=7.6605$, appropriate units as in the tables and in the earlier text.

Finally, taking the parameters obtained for the CITY route, fuel consumption and exhaust emissions were determined for several routes belonging to a given category. 
The results for all urban routes listed in Table I are summarized in Table III. In each case, fuel consumption has decreased and the acceleration times and gradeability are better than in the original model. Emissions of harmful substances have also decreased in most cases. Furthermore, taking into account the fact that our goal is to develop a strategy for the city vehicle, for the same number of energy storage $\left(\mathrm{N}_{\mathrm{BT}}\right.$ and $\left.\mathrm{N}_{\mathrm{UC}}\right)$ as in the CITY route, the optimization process was repeated for the HIGH and HIGH2 routes, assuming that some parameters of the management system strategy can be changed by the driver, e.g., by selecting $\mathrm{C} / \mathrm{H} / \mathrm{H} 2$.

The results are as follows: HIGH: $\mathrm{D}_{\mathrm{f}}=167, \mathrm{~S}_{\mathrm{A}}=0.0556$, $\mathrm{S}_{\mathrm{B}}=0.0716, \mathrm{~F}_{\mathrm{C}}=5.4696, \mathrm{E}_{\mathrm{HC}}=0.1821, \mathrm{E}_{\mathrm{CO}}=0.2515, \mathrm{E}_{\mathrm{NOX}}$ $=0.1268, \mathrm{~g}=16.883, \mathrm{a}_{\mathrm{c} 1}=3.8745, \mathrm{a}_{\mathrm{c} 2}=2.8709, \mathrm{a}_{\mathrm{c} 3}=$ 6.7453, HIGH2: $\mathrm{D}_{\mathrm{f}}=3503, \mathrm{~S}_{\mathrm{A}}=0.1630, \mathrm{~S}_{\mathrm{B}}=0.8889, \mathrm{~F}_{\mathrm{C}}=$ $6.5135, \mathrm{E}_{\mathrm{HC}}=0.1995, \mathrm{E}_{\mathrm{CO}}=0.2717, \mathrm{E}_{\mathrm{NOX}}=0.1473, \mathrm{~g}=$ 16.568, $\mathrm{a}_{\mathrm{c} 1}=4.4053, \mathrm{a}_{\mathrm{c} 2}=3.3797, \mathrm{a}_{\mathrm{c} 3}=7.785$. Fuel consumption and harmful substance emissions for the Prius v2.0 model for the CITY, HIGH, and HIGH2 drive cycles model, for comparison with the results summarized in Table II, are presented in Table IV. Figures 7-9 show plots that illustrate the significant changes in selected quantities from the point of view of the operation of the energy storage system. For the sake of illustration, the focus is on the CITY cycle. Figure 7(a) shows the speed profile as a function of time. For easier interpretation and comparison, this plot was repeated in Fig. 8(a). The remaining plots in Fig. 7 refer to the original PRIUS model, and in Figs. 8 and 9, they refer to the proposed model after optimization. Differences can be seen when we compare the simulation results of the original Toyota Prius with the modified version 2.0. As a result of the use of additional energy storage, the value of the charging/discharging current and the number of on/off cycles of the primary power source have decreased (Fig. 7(c) and Fig. 8(b)). In conditions where there is a need to operate with high current values (accelerating/braking of the car), the supercapacitor is used (Fig. 8(c)). The proposed strategy led to a reduction in the number of charging and discharging cycles, as well as the value of the battery currents, and as a result, reduced its temperature from $35^{\circ} \mathrm{C}$ to $28^{\circ} \mathrm{C}$ (Fig. 7(d) and 9(c)).

When analyzing the state of charge of the battery (Fig. 7(b) and Fig. 9(a)), it is easy to see that in the initial period, up to about $600 \mathrm{~s}$, the value decreases from the initial 0.7 to about 0.5 . This is accompanied by an almost linear increase in temperature. Next, slight fluctuations in SOC can be observed. This justifies, for proper interpretation, the need to consider routes with a length of at least $10 \mathrm{~km}$ so that the initial SOC does not play a significant role. The plot shown in Fig. 9(b) confirms that the UC storage system correctly performs its role. The state of charge changes in the assumed range from 0.05 to 0.95 , taking over the role or supporting the operation of the battery.

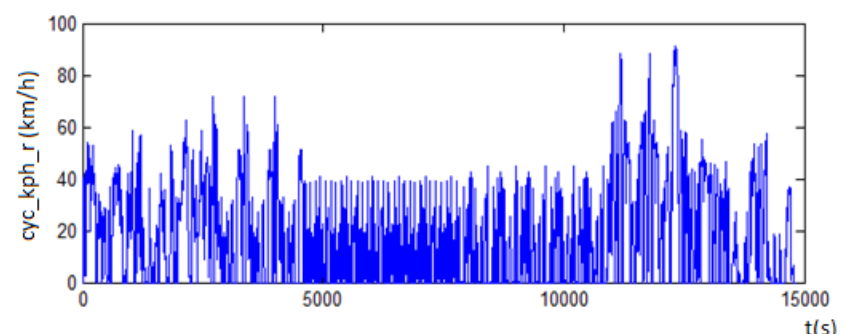

(a)

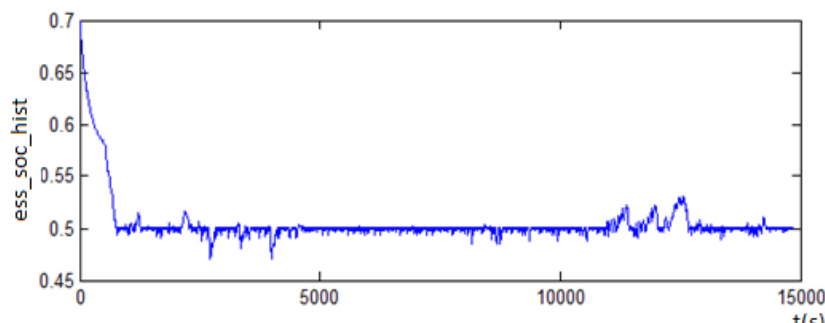

(b)

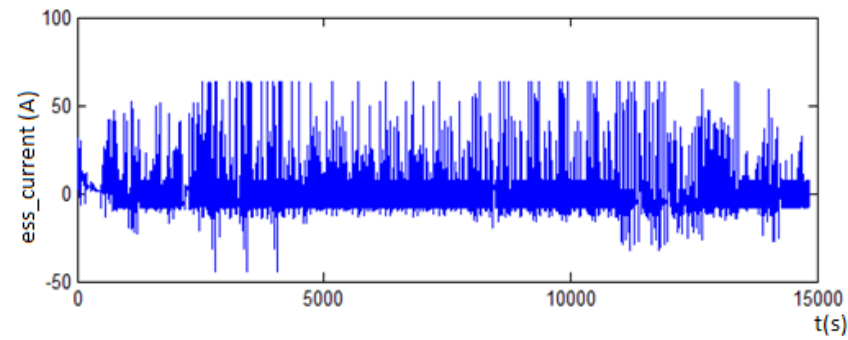

(c)

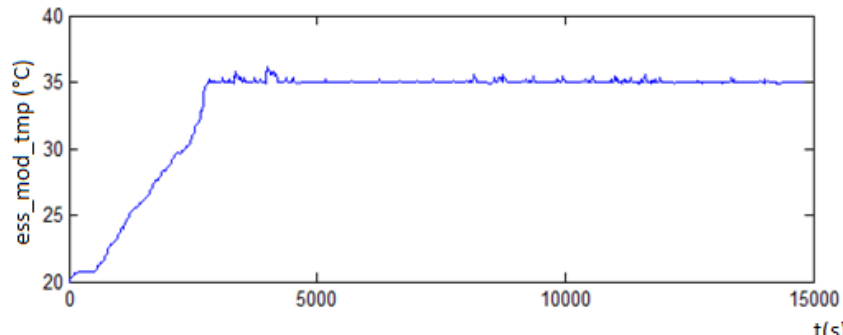

(d)

Fig. 7. Simulation results for the CITY drive cycle (original Toyota Prius) (a) vehicle speed; (b) battery SOC; (c) battery current; (d) battery temperature.

TABLE III. THE AGGREGATED ROUTES, FUEL CONSUMPTION AND EMISSIONS OF HARMFUL SUBSTANCES FOR PRIUS V2.0 $\left(\mathrm{N}_{\mathrm{BT}}=35\right.$, $\left.\mathrm{N}_{\mathrm{UC}}=77\right)$.

\begin{tabular}{|c|c|c|c|c|c|c|}
\hline No. & Route & Distance $[\mathbf{k m}]$ & FC $[\mathbf{l} / \mathbf{1 0 0} \mathbf{~ k m}]$ & $\mathbf{H C}[\mathbf{g} / \mathbf{k m}]$ & $\mathbf{C O}[\mathbf{g} / \mathbf{k m}]$ & $\mathbf{N O x}[\mathbf{g} / \mathbf{k m}]$ \\
\hline 1 & INDIA_URBAN x2 & 35.00 & 5.3577 & 0.3937 & 0.4242 & 0.1063 \\
\hline 2 & Lodz2 x8 & 28.40 & 7.2075 & 0.4713 & 0.5443 & 0.1502 \\
\hline 3 & Manhattan x8 & 26.60 & 9.4690 & 0.6507 & 0.6156 & 0.1325 \\
\hline 4 & NYCC x15 & 28.30 & 9.9743 & 0.6248 & 0.6002 & 0.1471 \\
\hline 5 & NurembergR36 x6 & 25.90 & 8.2433 & 0.5889 & 0.5415 & 0.1106 \\
\hline 6 & Wvucity x5 & 26.60 & 6.8545 & 0.5670 & 0.5143 & 0.0850 \\
\hline
\end{tabular}

TABLE IV. THE AGGREGATED ROUTES, FUEL CONSUMPTION AND EMISSIONS OF HARMFUL SUBSTANCES FOR PRIUS V2.0 $\left(\mathrm{N}_{\mathrm{BT}}=35\right.$, $\left.\mathrm{N}_{\mathrm{UC}}=77\right)$.

\begin{tabular}{|c|c|c|c|c|c|c|}
\hline No. & Route & Distance $[\mathbf{k m}]$ & FC $[\mathbf{l} / \mathbf{1 0 0} \mathbf{k m}]$ & $\mathbf{H C}[\mathbf{g} / \mathbf{k m}]$ & $\mathbf{C O}[\mathbf{g} / \mathbf{k m}]$ & $\mathbf{N O x}[\mathbf{g} / \mathbf{k m}]$ \\
\hline 1 & CITY & 76.46 & 6.7074 & 0.3411 & 0.3517 & 0.1089 \\
\hline 2 & HIGH & 116.77 & 5.4696 & 0.1821 & 0.2515 & 0.1268 \\
\hline 3 & HIGH2 & 117.43 & 6.5135 & 0.1995 & 0.2717 & 0.1473 \\
\hline
\end{tabular}




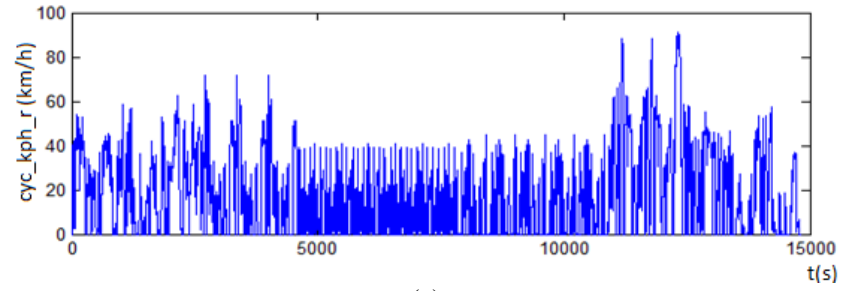

(a)

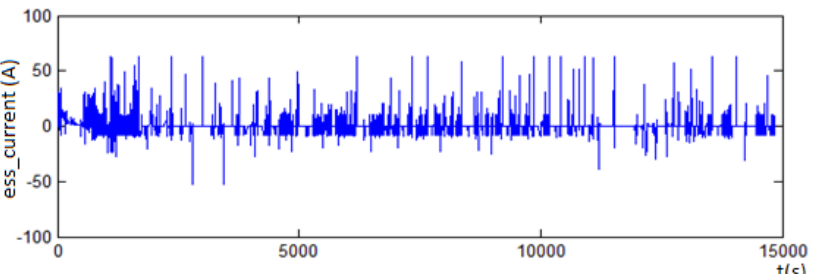

(b)

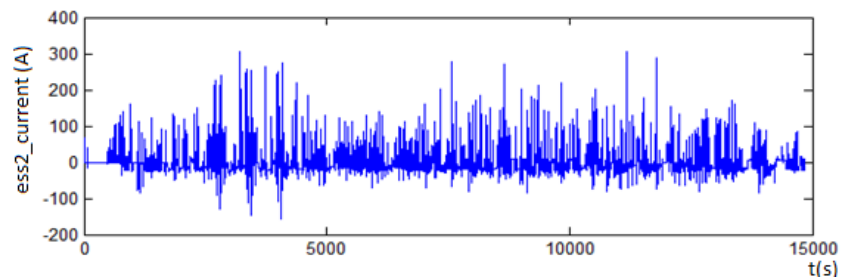

(c)

Fig. 8. Simulation results for CITY drive cycle (Prius 2.0): (a) vehicle speed; (b) battery current; (c) ultracapacitor current.

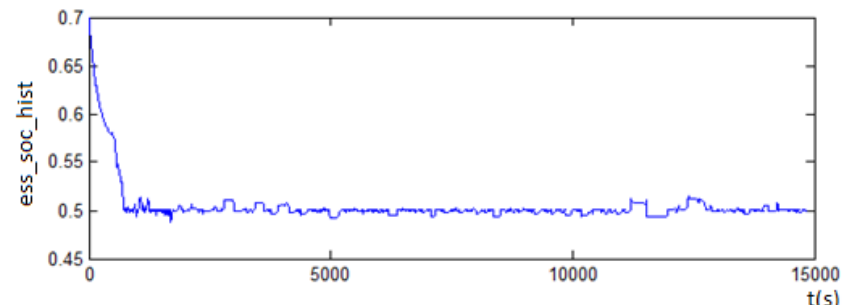

(a)

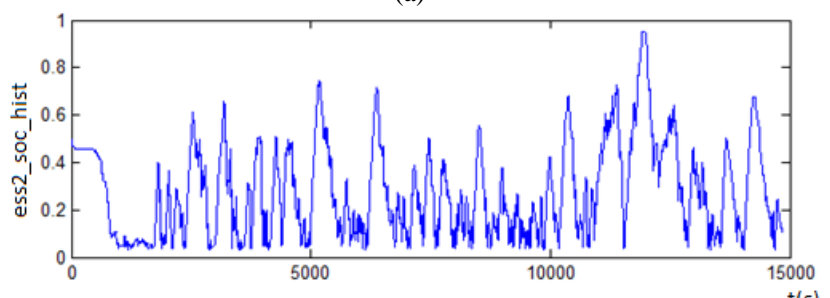

(b)

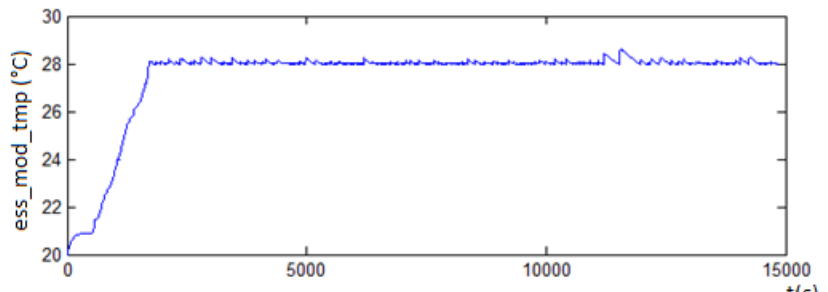

(c)

Fig. 9. Simulation results for the CITY drive cycle (Prius 2.0): (a) battery SOC; (b) ultracapacitor SOC; (c) battery temperature.

Figures 10 and 11 show selected simulation results of an optimized energy management system for the HIGH and HIGH2 driving cycles (SOC plots for both energy storage systems). Due to the suburban nature of these driving cycles, the number of stops and starts is significantly lower than in the CITY driving cycle (Fig. 4(b), Fig. 5(b), and Fig. 6(b)). By analysing these and other plots, not included in the paper, one can observe the operation of both energy storage devices following the assumptions of the proposed strategy.

In particular, with large changes in speed (e.g., time intervals of $1800 \mathrm{~s}$ to $2600 \mathrm{~s}$ for the HIGH cycle and $2600 \mathrm{~s}$ to $3000 \mathrm{~s}$ for the HIGH2 cycle), large changes in the SOC for UC and no or small changes in SOC for BT can be observed. This is also confirmed by the current plots for both energy storage systems.

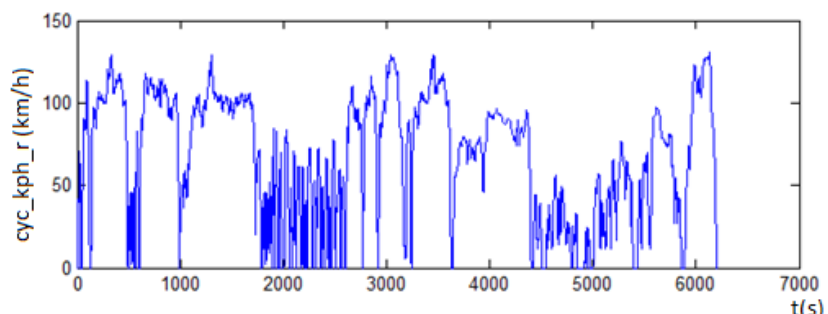

(a)

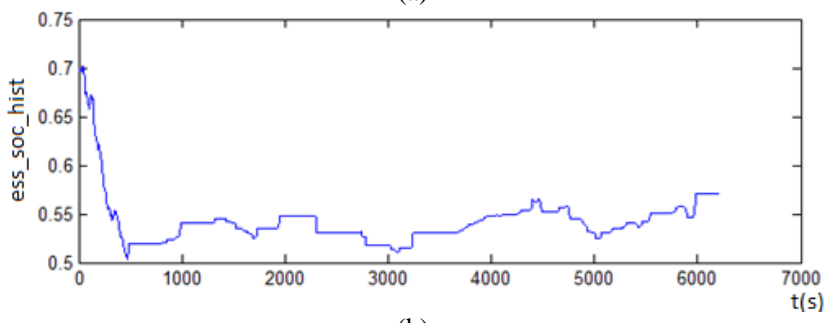

(b)

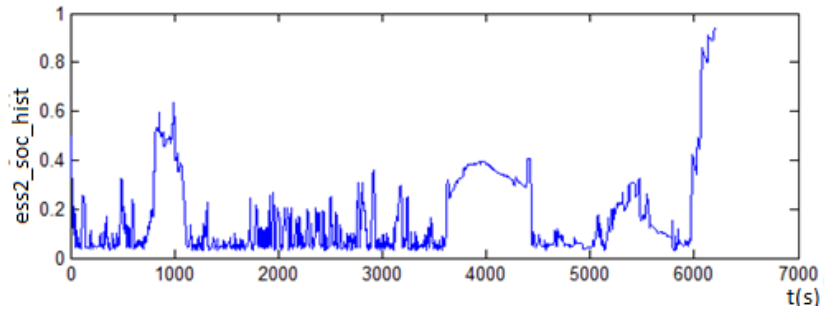

(c)

Fig. 10. Simulation results for HIGH drive cycle (Prius 2.0): (a) vehicle speed; (b) battery SOC; (c) ultracapacitor SOC.

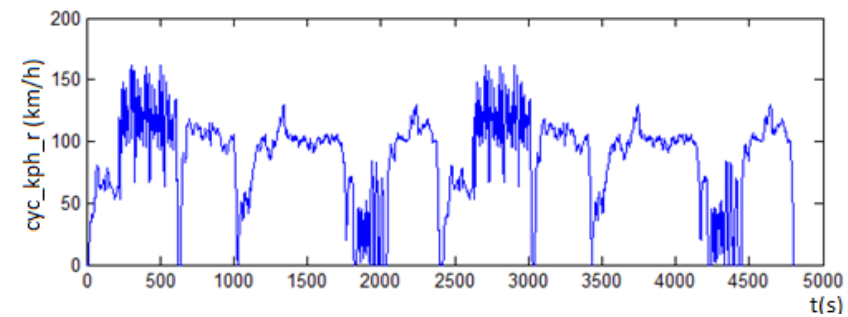

(a)

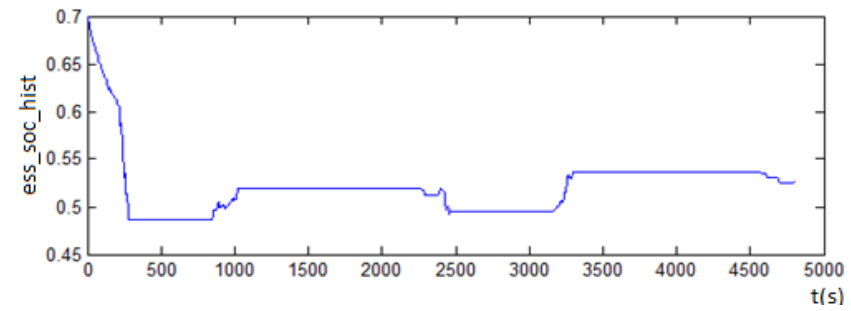

(b)

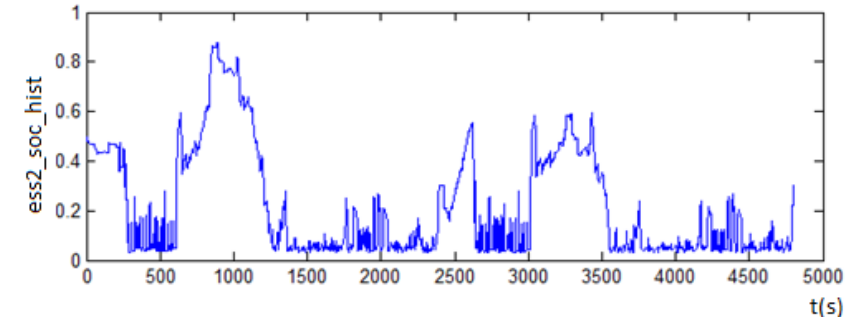

(c)

Fig. 11. Simulation results for HIGH2 drive cycle (Prius 2.0): (a) vehicle speed; (b) battery SOC; (c) ultracapacitor SOC.

The operating temperature of the BT storage system does 
not exceed 28 degrees for the HIGH cycle and 30 degrees for the HIGH2 cycle. Similarly to the CITY route, it can be seen that the initial fragment in both cases is dominated by the initial state of charge of the batteries.

\section{Multiobjective Optimization}

The presence of multiple variables in a problem gives rise to a set of optimal solutions, rather than a single optimal solution. Classic optimization methods are based on converting the multiobjective optimization problem to a single-objective optimization problem by emphasizing one particular Pareto-optimal solution at a time. Therefore, the results of the optimization process based on the DIRECT procedure were verified using the NSGA-II multiobjective genetic algorithm [28]. Multiobjective evolutionary algorithms that use nondominated sorting and sharing have been criticized mainly for their computational complexity, nonelitism approach, and the need to specify a sharing parameter. The NSGA-II algorithm alleviates all these difficulties, and in most problems, it is able to find a much better spread of solutions and better convergence near the true Pareto-optimal front. The same vector of optimized parameters as in the case of the DIRECT algorithm and the same limits $\mathbf{x}_{\mathbf{L}}$ and $\mathbf{x}_{\mathbf{U}}$ of the search for solutions were kept. Three objective functions are defined:

$$
\begin{gathered}
\mathrm{f}_{1}=\mathrm{w}_{1} \frac{\mathrm{F}_{\mathrm{c}}}{\mathrm{F}_{\mathrm{c} 1}}+\mathrm{w}_{2} \frac{\mathrm{E}_{\mathrm{HC}}}{\mathrm{E}_{\mathrm{HC} 1}}+\mathrm{w}_{3} \frac{\mathrm{E}_{\mathrm{CO}}}{\mathrm{E}_{\mathrm{CO} 1}}+\mathrm{w}_{4} \frac{\mathrm{E}_{\mathrm{NOX}}}{\mathrm{E}_{\mathrm{NOX} 1}}, \\
\mathrm{f}_{2}=-\mathrm{w}_{5} \frac{\mathrm{g}}{\mathrm{g}_{1}}, \\
\mathrm{f}_{3}=\mathrm{w}_{6} \frac{\mathrm{a}_{\mathrm{c} 1}}{\mathrm{a}_{1}}+\mathrm{w}_{7} \frac{\mathrm{a}_{\mathrm{c} 2}}{\mathrm{a}_{2}}+\mathrm{w}_{8} \frac{\mathrm{a}_{\mathrm{cs}}}{\mathrm{a}_{\mathrm{s}}} .
\end{gathered}
$$

We select the following weight values: 0.94, 0.02, 0.02, $0.02,1.00,0.33,0.33,0.33$. The main population size parameters of NSGA II - 100 and the total number of generations - 50 were selected. The results for the CITY drive cycle are as follows. The minimum function $f_{1}$ was obtained for $\mathrm{N}_{\mathrm{BT}}=33, \mathrm{~N}_{\mathrm{UC}}=74, \mathrm{D}_{\mathrm{f}}=1055, \mathrm{~S}_{\mathrm{A}}=0.0517, \mathrm{~S}_{\mathrm{B}}$ $=0.0520$ leading to $\mathrm{F}_{\mathrm{c}}=6.7200, \mathrm{E}_{\mathrm{HC}}=0.3435, \mathrm{E}_{\mathrm{CO}}=$ $0.3616, \mathrm{E}_{\mathrm{NOX}}=0.1123, \mathrm{~g}=16.661, \mathrm{a}_{\mathrm{c} 1}=4.0473, \mathrm{a}_{\mathrm{c} 2}=$ 3.1374, $\mathrm{a}_{\mathrm{c} 3}=7.1847$. The minimum function $\mathrm{f}_{2}$ was obtained for $\mathrm{N}_{\mathrm{BT}}=35, \mathrm{~N}_{\mathrm{UC}}=69, \mathrm{D}_{\mathrm{f}}=1333, \mathrm{~S}_{\mathrm{A}}=0.0566, \mathrm{~S}_{\mathrm{B}}=$ 0.0510 . Taking these parameter values, the following results were obtained: $\mathrm{F}_{\mathrm{c}}=6.7873, \mathrm{E}_{\mathrm{HC}}=0.3436, \mathrm{E}_{\mathrm{CO}}=0.3616$, $\mathrm{E}_{\mathrm{NOX}}=0.1135, \mathrm{~g}=16.827, \mathrm{a}_{\mathrm{c} 1}=4.0674, \mathrm{a}_{\mathrm{c} 2}=3.1563, \mathrm{a}_{\mathrm{c} 3}=$ 7.2236. The minimum function $\mathrm{f}_{3}$ was obtained for $\mathrm{N}_{\mathrm{BT}}=$ $34, \mathrm{~N}_{\mathrm{UC}}=74, \mathrm{D}_{\mathrm{f}}=1000, \mathrm{~S}_{\mathrm{A}}=0.1205, \mathrm{~S}_{\mathrm{B}}=0.1235$. With these parameter values, the following results were obtained: $\mathrm{F}_{\mathrm{C}}=6.9748, \mathrm{E}_{\mathrm{HC}}=0.3464, \mathrm{E}_{\mathrm{CO}}=0.3525, \mathrm{E}_{\mathrm{NOX}}=0.1107, \mathrm{~g}$ $=16.753, \mathrm{a}_{\mathrm{c} 1}=4.0412, \mathrm{a}_{\mathrm{c} 2}=3.1409, \mathrm{a}_{\mathrm{c} 3}=7.1821$. When analyzing the results obtained, it can be seen that both optimization methods lead to similar values for $\mathrm{N}_{\mathrm{BT}}$ and

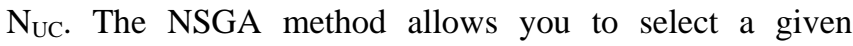
combination of parameters to minimize a given objective function or to choose a set of optimal parameters for two or three objective functions. Unfortunately, this method is more time-consuming than the DIRECT method.

Additionally, by defining the appropriate objective functions, using the NSGA II algorithm, an optimization process was carried out to determine the parameters of the proposed strategy while maintaining fuel combustion, exhaust emissions, and other vehicle parameters as for the original PRIUS model. As a result, the following parameters were obtained: $\mathrm{N}_{\mathrm{BT}}=26, \mathrm{~N}_{\mathrm{UC}}=41, \mathrm{D}_{\mathrm{f}}=1000, \mathrm{~S}_{\mathrm{A}}=0.948$, $\mathrm{S}_{\mathrm{B}}=0.202$ leading to $\mathrm{F}_{\mathrm{c}}=7.2577, \mathrm{E}_{\mathrm{HC}}=0.3567, \mathrm{E}_{\mathrm{CO}}=$ $0.3364, \mathrm{E}_{\mathrm{NOX}}=0.1025, \mathrm{~g}=14.385, \mathrm{a}_{\mathrm{c} 1}=4.2795, \mathrm{a}_{\mathrm{c} 2}=$ $3.6338, \mathrm{a}_{\mathrm{c} 3}=7.9133$. Figure 12 shows some plots related to the CITY drive cycle. On their basis, it can be concluded that the use of an additional energy storage system allows for extending the service life of the main storage system by reducing the number of charging/discharging cycles and its temperature.

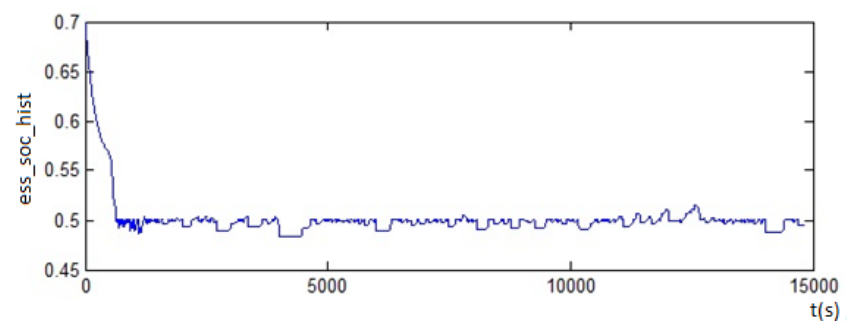

(a)

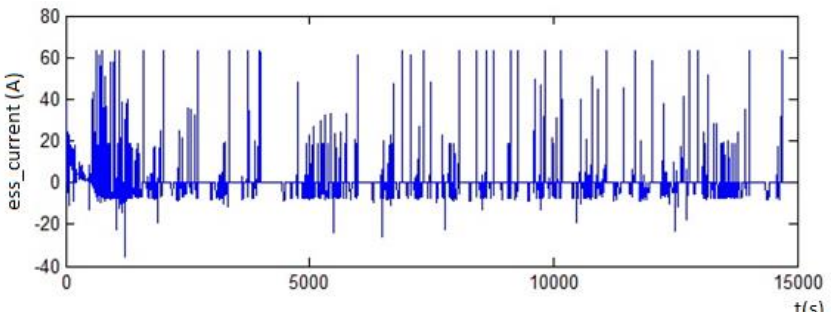

(b)

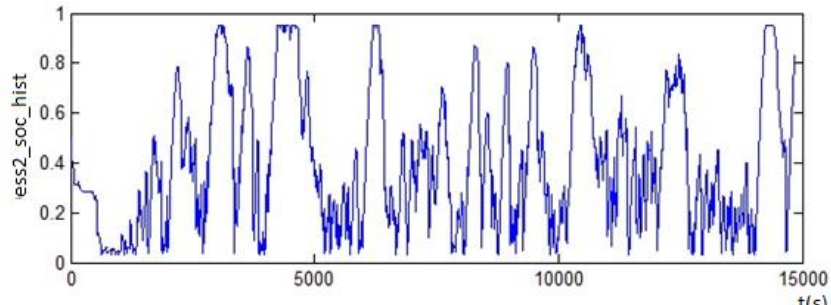

(c)

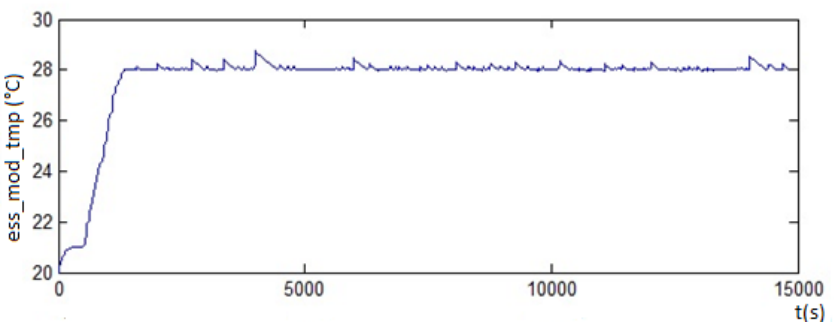

(d)

Fig. 12. Simulation results for the CITY drive cycle: (a) battery SOC; (b) battery current; (c) ultracapacitor SOC; (d) battery temperature.

\section{CONCLUSIONS}

The main achievement of the work is the original design of the energy management strategy in the hybrid vehicle with mixed drive used in the Toyota Prius and the optimization of its parameters. Contrary to many works in this area, the proposed strategy takes into account, at the optimization stage, by formulating appropriate objective functions, many aspects affecting the final result, i.e., fuel consumption, exhaust emissions, parameters determining vehicle dynamics, main reservoir temperature, route profile. The optimization process was performed on an aggregated 
route and then comprehensive tests were carried out on various routes. A procedure was proposed for the driver to select the route mode $(\mathrm{C} / \mathrm{H} / \mathrm{H} 2)$, which, with the assumed number of storage tanks, made it possible to change the parameters of the energy management system to those optimized for the planned route. The results obtained show that the energy management systems presented, using HESS, have brought many benefits. If the aim of the optimization process is to reduce fuel consumption exhaust emissions and, at the same time, to improve driving dynamics and gradeability, in most cases, the optimization process led to the number of BT and UC modules close to the upper limits of the assumed parameter range. However, if the goal of the process is to maintain these parameters as in the original model, the proposed strategy allows a significant reduction in the number of BT modules (from 40 in the original PRIUS model to 26) with a relatively small number (41) of UC modules. In the proposed strategy, it is possible to switch between three sets of strategy parameters at the driver level, depending on the planned type of route. Moreover, when the profile of the planned route is known in advance, the use of the GPS allows additional use of the energy stored in the auxiliary energy storage system. The parameters of the energy management system depend on the adopted weights and the assumed temperature limits $\left(\mathrm{T}^{-}, \mathrm{T}\right.$ $\left.{ }^{+}\right)$that were assumed. By changing the weights, other parameters can be obtained, leading, e.g., to lower fuel consumption at the expense of higher exhaust emissions and lower vehicle dynamics. In such considerations, the analysis of the Pareto fronts may be helpful. A certain limitation in the use of the NSGA II method is its time-consuming nature. An optimization process, with fixed weights, takes up to 48 hours. Currently, research is carried out in which it plans to accelerate this process by using several algorithms in one process, e.g. the differential evolution algorithm and particle swarm optimization. Acceleration of the optimization process will allow us to examine the impact of other important parameters, i.e., ambient temperature, use of air conditioning, etc., on the final result.

Vehicle economics have been improved by using an additional energy storage system in the form of UC modules while reducing the number of BT modules. Optimal internal combustion engine operating conditions resulted in a reduction in fuel consumption and the emission of harmful substances for most of the driving cycles tested. Additional energy storage has relieved the main energy storage. Comparing the results shown in Figs. 7 and 12, it can be seen that the reduced number of charge/discharge cycles and the value of the currents of the BT ESS resulted in a lower operating temperature. It means that the main energy storage system works under more favorable conditions, which extends its operation time. Supercapacitors have a much longer life compared to regular batteries. The number of charging and discharging cycles declared by the manufacturers reaches the value of 1000000 . In addition, supercapacitors can receive and deliver a large amount of energy in very short time. The cooperation of these two types of energy storage systems and the proper management of the energy stored in them allowed achieving better performance of the vehicle tested.

\section{ACKNOWLEDGMENT}

The author thanks Professor S. Hałgas for the useful discussion he had with him.

\section{CONFLICTS OF INTEREST}

Author declares that he has no conflict of interest.

\section{NOMENCLATURE}

\begin{tabular}{|c|c|}
\hline ICE & Internal combustion engine \\
\hline EV & Electric vehicle \\
\hline $\mathrm{HEV}$ & Hybrid electric vehicle \\
\hline $\mathrm{CO}$ & Carbon oxides \\
\hline $\mathrm{NO}_{\mathrm{x}}$ & Nitrogen oxides \\
\hline $\mathrm{HC}$ & Hydrocarbons \\
\hline SOC & State of charge (battery) \\
\hline SOC2 & State of charge (ultracapacitor) \\
\hline EMS & Energy management system \\
\hline HESS & Hybrid energy storage system \\
\hline GUI & Graphical user interface \\
\hline Li-ion & Lithium-ion battery \\
\hline $\mathrm{Ni}-\mathrm{MH}$ & Nickel metal hydride battery \\
\hline UC & Ultracapacitor state (on/off) \\
\hline BT & Battery state (on/off) \\
\hline BT-1 & Battery state from previous cycle (on/off) \\
\hline GPS & Global positioning system \\
\hline $\mathrm{N}_{\mathrm{BT}}$ & Number of battery modules \\
\hline $\mathrm{N}_{\mathrm{UC}}$ & Number of ultracapacitor modules \\
\hline $\mathrm{S}_{\mathrm{BT} 0}$ & Initial value of SOC \\
\hline $\mathrm{S}_{\mathrm{UC} 0}$ & Initial value of SOC2 \\
\hline$\left(\mathrm{S}_{\mathrm{L}}\right)_{\mathrm{BT}}$ & Lower limit of SOC \\
\hline$\left(\mathrm{S}_{\mathrm{H}}\right)_{\mathrm{BT}}$ & Upper limit of SOC \\
\hline$\left(\mathrm{S}_{\mathrm{L}}\right)_{\mathrm{UC}}$ & Lower limit of SOC2 \\
\hline$\left(\mathrm{S}_{\mathrm{H}}\right)_{\mathrm{UC}}$ & Upper limit of SOC2 \\
\hline $\mathrm{D}_{\mathrm{f}}$ & Limit value of time derivative of power \\
\hline $\mathrm{T}^{-}$ & Lower limit of the temp. hysteresis loop \\
\hline $\mathrm{T}^{+}$ & Upper limit of the temp. hysteresis loop \\
\hline $\mathrm{T}_{\mathrm{BT}}$ & Current value of battery temperature \\
\hline $\mathrm{F}_{\mathrm{c}}$ & fuel consumption \\
\hline $\mathrm{E}_{\mathrm{HC}}$ & emissions of $\mathrm{HC}$ \\
\hline $\mathrm{E}_{\mathrm{CO}}$ & emissions of $\mathrm{CO}$ \\
\hline $\mathrm{E}_{\mathrm{NOx}}$ & emissions of NOx \\
\hline $\mathrm{g}$ & gradeability \\
\hline$a_{c 1}$ & acceleration time $(0 \mathrm{~km} / \mathrm{h}-40 \mathrm{~km} / \mathrm{h})$ \\
\hline$a_{c 2}$ & acceleration time $(40 \mathrm{~km} / \mathrm{h}-60 \mathrm{~km} / \mathrm{h})$ \\
\hline $\mathrm{a}_{\mathrm{c} 3}$ & acceleration time $(0 \mathrm{~km} / \mathrm{h}-60 \mathrm{~km} / \mathrm{h})$ \\
\hline temp & Initial value of battery temperature \\
\hline ess_mod_tmp & Registered value of battery temperature \\
\hline ess_current & Registered value of battery current \\
\hline ess2_current & Registered value of ultracapacitor current \\
\hline cyc_kph & Registered value of speed \\
\hline
\end{tabular}

\section{REFERENCES}

[1] IEA Global EV Outlook 2020, IEA. [Online]. Available: https://www.iea.org/reports/global-ev-outlook-2020

[2] C. Randall, "EU to tighten Euro 7 emissions standard for all tests", $\begin{array}{lll}\text { electrive.com. } & \text { [Online]. Available: }\end{array}$ https://www.electrive.com/2020/11/16/vda-worried-about-the-euro-7emissions-standard/

[3] J. Pielecha, K. Skobiej, and K. Kurtyka, "Exhaust emissions and energy consumption analysis of conventional, hybrid, and electric vehicles in real driving cycles", Energies, vol. 13, no. 23, p. 6423, 
2020. DOI: $10.3390 /$ en 13236423

[4] R. Bosch, Hybrid Drives, Fuel Cells and Alternative Fuels, 1st ed. Bentley Publishers: Cambridge MA 02138-1804, USA, 2010.

[5] C. Zhao, B. Zhang, Y. Zheng, S. Huang, T. Yan, and X. Liu, "Hybrid battery thermal management system in electrical vehicles: A review", Energies, vol. 13, no. 23, p. 6257, 2020. DOI: 10.3390/en13236257.

[6] L. Kouchachvili, W. Yaici, and E. Entchev, "Hybrid battery/supercapacitor energy storage system for the electric vehicles", Journal of Power Sources, vol. 374, pp. 237-248, 2018. DOI: 10.1016/j.jpowsour.2017.11.040.

[7] A. King, "Power-hungry Tesla picks up supercapacitor maker", ChemistryWorld. [Online]. Available: https://www.chemistryworld.com/news/power-hungry-tesla-picks-upsupercapacitor-maker-/3010215.article

[8] A. C. Baisden and A. Emadi, "ADVISOR-based model of a battery and an ultra-capacitor energy source for hybrid electric vehicles", IEEE Transactions on Vehicular Technology, vol. 53, no. 1, pp. 199205, 2004. DOI: 10.1109/TVT.2003.822004.

[9] W. Gao, "Performance comparison of a fuel cell-battery hybrid powertrain and a fuel cell-ultracapacitor hybrid powertrain", IEEE Transactions on Vehicular Technology, vol. 54, no. 3, pp. 846-855, 2005. DOI: 10.1109/TVT.2005.847229.

[10] D. W. Gao, C. Mi, and A. Emadi, "Modeling and simulation of electric and hybrid vehicles", Proceedings of the IEEE, vol. 95, no. 4 pp. 729-745, 2007. DOI: 10.1109/JPROC.2006.890127.

[11] K. Gokce and A. Ozdemir, "A rule based power split strategy for battery/ultracapacitor energy storage systems in hybrid electric vehicles", International Journal of Electrochemical Science, vol. 11, pp. 1228-1246, 2016.

[12] L. H. Saw, H. M. Poon, W. T. Chong, C.-T. Wang, M. C. Yew, M. K. Yew, and T. C. Ng, "Numerical modeling of hybrid supercapacitor battery energy storage system for electric vehicles", Energy Procedia, vol. 158, pp. 2750-2755, 2019. DOI: 10.1016/j.egypro.2019.02.033.

[13] J. L. Sampietro, V. Puig, and R. Costa-Castelló, "Optimal sizing of storage elements for a vehicle based on fuel cells, supercapacitors, and batteries", Energies, vol. 12, no. 5, p. 925, 2019. DOI: 10.3390/en12050925.

[14] R. M. Asif, A. Yousaf, A. U. Rehman, N. Shabbir, and M. T. Sadiq, "Increase battery time by improvement in regenerative braking with storage system in hybrid vehicle", Journal of Applied and Emerging Sciences, vol. 9, no. 1, pp. 53-62, 2019. DOI: 10.36785/jaes.91260.

[15] Y. Yu, X. Liu, H. Min, H. Sun, and L. Xu, "A novel fuzzy-logic based control strategy for a semi-active battery/super-capacitor hybrid energy storage system in vehicular applications", Journal of Intelligent \& Fuzzy Systems, vol. 29, no. 6, pp. 2575-2584, 2015. DOI: 10.3233/IFS-151960.

[16] X. Peng, Q. Shuhai, and X. Changjun, "A new supercapacitor and Liion battery hybrid system for electric vehicle in ADVISOR", Journal of Physics Conference Series, vol. 806, art. ID 012015, 2017. DOI: 10.1088/1742-6596/806/1/012015.

[17] Y. Hu, W. Li, K. Xu, T. Zahid, F. Qin, and C. Li, "Energy management strategy for a hybrid electric vehicle based on deep reinforcement learning", Applied Sciences, vol. 8, no. 2, p. 187, 2018. DOI: $10.3390 /$ app8020187.

[18] J. Shen, S. Dusmez, and A. Khaligh, "Optimization of sizing and battery cycle life in battery/ultracapacitor hybrid energy storage systems for electric vehicle applications", IEEE Transactions on Industrial Informatics, vol. 10, no. 4, pp. 2112-2121, 2014. DOI: 10.1109/TII.2014.2334233.

[19] S. Hu, Z. Liang, W. Zhang, and X. He, "Research on the integration of hybrid energy storage system and dual three-phase PMSM drive in EV', IEEE Transactions on Industrial Electronics, vol. 65, no. 8, pp. 6602-6611, 2018. DOI: 10.1109/TIE.2017.2752141.

[20] C. Zhao, H. Yin, and C. Ma, "Equivalent series resistance-based realtime control of battery-ultracapacitor hybrid energy storage systems", IEEE Transactions on Industrial Electronics, vol. 67, no. 3, pp. 19992008, 2020. DOI: 10.1109/TIE.2019.2901640.

[21] F. Akar, Y. Tavlasoglu, and B. Vural, "An energy management strategy for a concept battery/ultracapacitor electric vehicle with improved battery life", IEEE Transactions on Transportation Electrification, vol. 3, no. 1, pp. 191-200, 2017. DOI: 10.1109/TTE.2016.2638640.

[22] X. Zeng, C. Cui, Y. Wang, G. Li, and D. Song, "Segemented driving cycle based optimization of control parameters for power-split hybrid electric vehicle with ultracapacitors", IEEE Access, vol. 7, pp. 9066690677, 2019. DOI: 10.1109/ACCESS.2019.2926504

[23] S. Kurm and V. Agarwal, "Hybrid energy storage system based on a novel reduced rating multi-input converter", IEEE Transactions on Power Electronics, vol. 35, no. 11, pp. 12133-12142, 2020. DOI: 10.1109/TPEL.2020.2987833.

[24] C. Zhang, D. Wang, B. Wang, and F. Tong, "Battery degradation minimization-oriented hybrid energy storage system for electric vehicles", Energies, vol. 13, no. 1, p. 246, 2020. DOI 10.3390/en13010246.

[25] F. Ortenzi, N. Andrenacci, M. Pasquali, and C. Villante, "On the hybridization of microcars with hybrid ultracapacitors and Li-ion batteries storage systems", Energies, vol. 13, no. 12, p. 3230, 2020. DOI: $10.3390 /$ en 13123230

[26] A. Biswas and A. Emadi, "Energy management systems for electrified powertrains: State-of-the-art review and future trends", IEEE Transactions on Vehicular Technology, vol. 68, no. 7, pp. 6453-6467, 2019. DOI: 10.1109/TVT.2019.2914457.

[27] L. Chiter, "DIRECT algorithm: A new definition of potentially optimal hyperrectangles", Applied Mathematics and Computation, vol. 179, no. 2, pp. 742-749, 2006. DOI: 10.1016/j.amc.2005.11.127.

[28] K. Deb, A. Pratap, S. Agarwal, and T. Meyarivan, "A fast and elitist multiobjective generic algorithm: NSGA-II", IEEE Transactions on Evolutionary Computation, vol. 6, no. 2, pp. 182-197, 2002. DOI: 10.1109/4235.996017.

[29] ADVISOR Advanced Vehicle Simulator. [Online]. Available: http://adv-vehicle-sim.sourceforge.net/

[30] D. Chen, X. Li, L. Chen, L. Yang, F. Tian, and D. Xu, "Research on simulation of the hybrid electric vehicle based on software ADVISOR", Sensors \& Transducers, vol. 171, no. 5, pp. 68-77, 2014.

[31] M. I. M. Rashid, H. Daniyal, and D. Mohamed, "Comparison performance of split plug-in hybrid electric vehicle and hybrid electric vehicle using ADVISOR", MATEC Web of Conferences, vol. 90, art. no. 01019, 2017. DOI: 10.1051/matecconf/20179001019.

[32] Y. Wu, "Power distribution system modeling and simulation of an alternative energy", M.S. thesis, Russ College of Engineering and Technology of Ohio University, Athens OH, USA, Nov. 2010.

[33] AVL CRUISE. [Online]. Available: https://www.avl.com/cruise

[34] Simcenter Amesim, Siemens. [Online]. Available: https://www.plm.automation.siemens.com/global/en/products/simcent er/simcenter-amesim.html

[35] Autonomie Vehicle System Simulation Tool, Argonne National Laboratory. [Online]. Available: https://www.anl.gov/es/autonomievehicle-system-simulation-tool

[36] PSIM HEV Design Suite, Powersim. [Online]. Available: https://powersimtech.com/products/psim/psim-modules/hev-designsuite/

[37] K. Clemens, "New and improved NREL automotive simulator predicts drivetrain efficiency", DesignNews. [Online]. Available: https://www.designnews.com/new-and-improved-nrel-automotivesimulator-predicts-drivetrain-efficiency

[38] C. W. Ng and L. Yossapong, "Comparison of electric bus power consumption modelling and simulation using basic power model, ADVISOR and FASTSim", in Proc. of 2020 2nd International Conference on Smart Power \& Internet Energy Systems (SPIES), 2020, pp. 414-419. DOI: 10.1109/SPIES48661.2020.9243058.

[39] Vehicle Technology Simulation and Analysis Tools, NREL Transforming ENERGY. [Online]. Available: http://web.archive.org/web/20210419064440/https://www.nrel.gov/tra nsportation/systems-analysis-tools.html

[40] P. Woźniak, "Hybrid energy storage system in hybrid vehicles: Design of energy management strategy and comparative analysis", Przeglad Elektrotechniczny, vol. 96, no. 8, pp. 55-59, 2020. DOI: 10.15199/48.2020.08.12

[41] K. J. Kelly and A. Rajagopalan, "Benchmarking of OEM hybrid electric vehicles at NREL", Milestone report, National Renewable Energy Laboratory, Golden CO, USA, Aug. 2001. DOI: 10.2172/788783

[42] K. J. Kelly, M. Mihalic, and M. Zolot, "Battery usage and thermal performance of the Toyota Prius and Honda Insight for various chassis dynamometer test procedures", in Proc. of 17th Annual Battery Conference on Applications and Advances, 2002, pp. 247 252. DOI: 10.1109/BCAA.2002.986408.

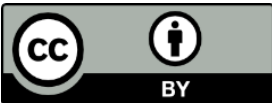

This article is an open access article distributed under the terms and conditions of the Creative Commons Attribution 4.0 (CC BY 4.0) license (http://creativecommons.org/licenses/by/4.0/). 